\title{
Alachlor oxidation by the filamentous fungus Paecilomyces marquandii
}

Journal of Hazardous Materials 261 (2013) 443- 450

http://dx.doi.org/10.1016/j.jhazmat.2013.06.064

Mirosława Słaba, Rafał Szewczyk, Milena Adela Piątek \& Jerzy Długoński*

*Department of Industrial Microbiology and Biotechnology, Faculty of Biology and Environmental Protection, University of Łódź, Banacha 12/16, 90237 Łódź, Poland, tel:+48-42-6354465, fax: +48-42-6655818, e-mail: jdlugo@biol.uni.lodz.pl

Keywords: alachlor, biooxidation, biotransformation, byproducts identification, Paecilomyces marquandii,

Abstract: Alachlor, a popular chloroacetanilide herbicide, can be a potential health risk factor. Soil microorganisms are primarily responsible for conversion and migration of alachlor in natural environment, but knowledge concerning alachlor biodegradation is not complete. Therefore, we studied the ability of Paecilomyces marquandii, soil fungus tolerant to heavy metals, to eliminate alachlor and proposed a new pathway of its transformation. After 7 days of incubation only $3.3 \%$ of alachlor was detected from an initial concentration 50 mg $\mathrm{L}^{-1}$ and $20.1 \%$ from a concentration $100 \mathrm{mg} \mathrm{L}^{-1}$. The qualitative IDA LC-MS analysis showed the presence of ten metabolites. All of them were dechlorinated mainly through oxidation, but also reductive dechlorination was observed. The main route of alachlor conversion progressed via $\mathrm{N}$-acetyl oxidation resulting in the formation of mono-, di- and trihydroxylated byproducts. $\mathrm{N}$-acetyl oxidation as a dominant route of alachlor metabolism by fungi has not been described so far. The toxicity of alachlor tested with Artemia franciscana did not increase after treatment with $P$. marquandii cultures. Paecilomyces marquandii strain seems to be an interesting model for the research on alachlor conversion by soil microscopic fungi, due to its dechlorination and hydroxylation ability as well as high tolerance to heavy metals.

\section{Introduction}

Alachlor [2-chloro- $N$-2,6-diethylphenyl- $N$-(methoxymethyl)acetamide] is a pre-emergence herbicide, widespread all over the world due to its effectiveness and moderate persistence in environment compared to other pesticides. Its solubility in water reaching $242 \mathrm{mg}$ $\mathrm{L}^{-1}$, low rate of mineralization and direct application into soil caused the leaching of alachlor into groundwater and migration in water environment [1]. This xenobiotic and its metabolites have been widely detected in rivers, sea, wastewater and drinking water [2]. Harmful effect of alachlor on human health has been proved by WHO [3]. Environmental Protection Agency (EPA, US) recognized this herbicide as slightly toxic (3rd class of toxicity). Based on the long-term animals study, alachlor was classified as a carcinogen of B2 group by EPA [4-6]. Additionally, alachlor was found to be a xenoestrogen, which disrupts the normal function of human and animal hormonal systems, modeling their activity in the way characteristic for female sexual hormones and it was included into the group of endocrine disrupting compounds (EDCs). Introduced to environment they cause a lot of unfavourable changes observed especially among animals living in marine and inland waters, such as malformation of sexual features, fertility disruptions and in consequence dying out of some species of bivalves, amphibians, fishes and mammalians[7-10]. The occurrence of xenoestrogens in drinking water can result in a wrong form of sex in the foetal period of humans and lead to cancer genesis [11-13]. For this reason, alachlor like most xenoestrogens was included in the European Union legislation [14] and Polish legislation [15 ] as a hazardous priority substance, which should be totally eliminated from environment.

The possibilities of alachlor elimination from water environment and drinking water by ozonation and advanced oxidation treatment are being intensively investigated [16]. A combined method of photoFenton and biological oxidation has also been used [17]. Microbiological degradation via cometabolism by different groups of microorganisms, representing soil microflora is a major way of its conversion in natural environment [18-19]. White et al. [20] reported that microscopic fungi are capable of degrading most chloroacetanilide herbicides. The genus of Paecilomyces represents ubiquitous soil fungi, often isolated from heavy metal polluted areas [21-23]. Its remarkable enzyme activity and degradative abilities were also documented [24-26] Literature data concerning alachlor degradation by soil microbial communities or pure microorganism cultures and their metabolic pathways are limited and usually reveal only a few byproducts [27-28]. Only Tiedje and Hagedorn, [29] and Sette et al. [30] documented the degradation of alachlor by pure cultures of soil fungus Chaetomium globosum and soil streptomycetes and proposed a microbial pathway of herbicide transformation.

In our earlier work the ability of Paecilomyces marquandii to simultaneously remove alachlor and zinc was estimated [31]. In the present study we focused on the identification of an alachlor degradation by-product, proposed a metabolic pathway and checked the toxicity of alachlor untreated and treated with $P$. marquandii.

\section{Materials and methods}

\subsection{Chemicals}

Ethyl acetate needed for alachlor extraction was purchased from POCH S.A. (Gliwice, Poland), whereas high purity solvents used during sample preparation for HPLC analysis were obtained from $\mathrm{J}$. T. Baker Chemical Co. (Netherlands). Alachlor, PESTANAL ${ }^{\circledR}$, analytical standard $(99.2 \%)$ and all the other chemicals were from Sigma-Aldrich Chemical Co. (Germany).

\subsection{Microorganism}

Paecilomyces marquandii S. Hughes, 1951 (basionym: Verticillium marquandii (Massee, 1898), a filamentous fungus from the collection of the Department of Industrial Microbiology and Biotechnology, University of Lodz (identification number: IM 6003) was tested in this work. This strain was selected from postflotation dumps of nonferrous metal works (Silesia, Poland), strongly polluted with heavy metals [32].

\subsection{P. marquandii culture conditions}

Ten-day-old spores obtained from ZT agar slants were used to inoculate $20 \mathrm{ml}$ Sabouraud medium (per liter: $10 \mathrm{~g}$ peptone, $20 \mathrm{~g}$ glucose) in $100 \mathrm{ml}$ Erlenmeyer flasks. The cultivation (with conidia density of $5 \times 10^{7} \mathrm{~mL}^{-1}$ ) was carried out on a rotary shaker (160 rpm) for $24 \mathrm{~h}$ at $28^{\circ} \mathrm{C}$. The preculture $(3 \mathrm{ml})$ was transferred to $17 \mathrm{ml}$ of fresh medium and incubated for the next $24 \mathrm{~h}$. The homogenous preculture $(15 \%)$, prepared as presented above, was introduced into Sabouraud medium, supplemented with alachlor at 50 and $100 \mathrm{mg}$ $\mathrm{L}^{-1}$ concentrations, or without the xenobiotic in the control cultures. Abiotic controls, containing the medium and alachlor at appropriate concentrations were also incubated. The cultures were grown for 7 days under standard conditions. Next, mycelia samples were separated for analyses. Biomass was washed with distilled water and dry weight was quantified by the method described by Różalska et al. [33].

\subsection{Alachlor extraction and samples preparation}

Samples were prepared according to the method described by Słaba et al. [31] with some modifications. The cultures were homogenized with $20 \mathrm{ml}$ ethyl acetate (MISONIX, England) at $4^{\circ} \mathrm{C}$ and with $120 \mathrm{~W}$ power input. After homogenization, the samples were extracted and this step was repeated with the second portion of ethyl acetate. Next, the extracts were dried with anhydrous sodium sulfate and evaporated under reduced pressure at $40^{\circ} \mathrm{C}$. Evaporated residues were dissolved in $2 \mathrm{ml}$ of ethyl acetate and $0.2 \mathrm{ml}$ was transferred to chromatography plates for quantitative and qualitative analyses.

\subsection{Cytochrome $P-450$ inhibition studies}

Proadifen $(0.1 \mathrm{mM})$ and 1-aminobenzotriazole $(1 \mathrm{mM})$ were introduced to $17 \mathrm{ml}$ Sabouraud medium inoculated with $3 \mathrm{ml}$ of fungal homogenous preculture. After $30 \mathrm{~min}$ alachlor $\left(50 \mathrm{mg} \mathrm{L}^{-1}\right)$ was 
added and the samples were incubated and prepared, as described above. Initial concentration of inhibitors was individually selected for $P$. marquandii as the highest dose, not inhibiting fungal growth by more than $15 \%$. During the samples incubation the inhibitors level was monitored chromatographically and in the case of depletion it was supplied to a proper concentration.

\subsection{HPLC-MS/MS analysis}

Analyses were performed on the Agilent 1200 LC System coupled with an AB Sciex 3200 QTRAP mass detector equipped with TurboSpray Ion Source (ESI). The column used was Agilent XDB$\mathrm{C} 18,1.8 \mu \mathrm{m}, 4.6 \times 50 \mathrm{~mm}$ and a mobile phase was a mixture of: $\mathrm{A}-$ $\mathrm{H}_{2} \mathrm{O}+5 \mathrm{mM}$ ammonium formate: $\mathrm{B}-\mathrm{ACN}+5 \mathrm{mM}$ ammonium formate.

\subsubsection{Quantitative analysis}

$10 \mu \mathrm{l}$ of the each tested sample was injected on a column maintained in isocratic conditions $A: B-20: 80$, temperature $30^{\circ} \mathrm{C}$ and $500 \mu \mathrm{min}^{-1}$ flow. The retention time of alachlor was $2.35 \mathrm{~min}$. MS/MS detection was made in an MRM positive ionization mode. Optimized MRM pairs for alachlor were: 270.1-238.2 m/z $(C E=13)-$ quantifier ion, 270.1-162.3 (CE=25) - qualifier ion. The other parameters of the detector were: CUR: 25.00; TEM: 600.00; GS1: 55.00; GS2: 40.00; interface heater: ON; IS: 5500.00; CAD: Medium; DP: 21.00; EP: 5.50; CEP: 14.00; CXP: 4.00. A standard equation used for the quantitative analysis showed linearity in the range from 0 to $10 \mu \mathrm{g} \mathrm{mL}^{-1}$ of alachlor $(r=0.9984)$.

\subsubsection{Qualitative analysis}

$10 \mu \mathrm{l}$ of the tested samples was injected on a column with mobile phase flow $500 \mu \mathrm{min}^{-1}$ and the temperature set at $30^{\circ} \mathrm{C}$. The following gradient was applied: $-2-0$ min preinjection equilibration $80: 20(A: B) ; 0-2 \min 80: 20(A: B) ; 20: 80(A: B)$ in $12 \mathrm{~min}$ and maintained until17 $\mathrm{min} ; 17.10$ reversed to start conditions $80: 20$ $(A: B)$ and maintained till the end of the method in $18.00 \mathrm{~min} . \mathrm{MS} / \mathrm{MS}$ detection was made in an IDA (Information Dependant Acquisition) mode composed of mixed scan modes and IDA criteria for dynamic $\mathrm{m} / \mathrm{z}$ filtering. The method was constructed as follows: Prec 1 (Precursor ion scan), Prec 2, ER (Enhanced Resolution scan), IDA criteria, EPI (Enhanced Product Ion scan). Precursors were 117.1 $\mathrm{m} / \mathrm{z}(\mathrm{DP}=15-25, C E=60-70)$ working in the range $120-280 \mathrm{~m} / \mathrm{z}$ and $162.1 \mathrm{~m} / \mathrm{z}(\mathrm{DP}=15-25, C E=20-30)$ working in the range $164-320 \mathrm{~m} / \mathrm{z}$. Both precursors were assigned as markers for potential alachlor metabolites. ER scan worked in $250 \mathrm{Da} / \mathrm{s}$ scan rate $(\mathrm{DP}=15-25)$ and it was used for isotopic distribution studies of molecular ion species. EPI scan was working in the range 50-320 m/z (DP=15-25, CE=40, $C E S=20$ ) and was used for mass spectra collection. The rest of the MS parameters were the same as in the quantitative method. The most important IDA criteria used for selective $\mathrm{m} / \mathrm{z}$ filtering were as follows: chosen 1 to 2 most intense peaks from the range 117-320 $\mathrm{m} / \mathrm{z}$, whose charge state was +1 and exceeded 10000 counts intensity, excluding former target ions for 30 s after 3 occurrences. Further explanation of the method setup is provided in the results section.

\subsection{Toxicity study}

Artemia franciscana (formerly $A$. salina) Artoxkit M (MicroBioTests, Inc., Mariakerke, Belgium) was used according to the standard producer's procedure. $A$. franciscana cysts were incubated in standard saline water for $30 \mathrm{~h}$ at $25^{\circ} \mathrm{C}$ at the lightness 3000 lux. The motile larvae were applied in an acute toxicity test. The cultures of $P$. marquandii with or without alachlor (control) were separated by filtration. The supernatant and abiotic samples containing alachlor at the same concentration as in biotic samples were extracted with ethyl acetate two times, dried with anhydrous sulfate and evaporated under reduced pressure at $40^{\circ} \mathrm{C}$. Evaporated samples were dissolved in $0.2 \mathrm{ml}$ ethanol and diluted with saline water to obtain the same volume as after filtration. Next, appropriate dilutions were performed. A. franciscana controls with saline water and with the same volume of ethanol as in the samples were also carried out. All samples with alachlor and controls were in three replicates and all tests were performed in triplicate.

\subsection{Statistical analysis}

All experiments were carried out in triplicate. One-way analysis of variance (ANOVA) was used to determine the significance of the differences between the samples. All statistical analyses were performed using Excel 2000 (Microsoft Corporation, USA).

\section{Results and discussion}

\subsection{Growth and removal of alachlor by $P$. marquandii}

The investigated fungus growth and alachlor elimination by $P$. marquandii in liquid Sabouraud medium amended with alachlor (50 and $100 \mathrm{mg}$ in 1 litre) has been illustrated in Fig.1. Both tested concentrations of alachlor inhibited growth of the fungus, but from $144 \mathrm{~h}$ the difference between the control and the culture with a 50 $\mathrm{mg} \mathrm{L}^{-1}$ dose of the herbicide did not have statistical importance (Fig.1). Toxic substrate applied at concentration of $100 \mathrm{mg} \mathrm{L}^{-1}$ repressed significantly fungal growth during the whole time of incubation (40-60\%).

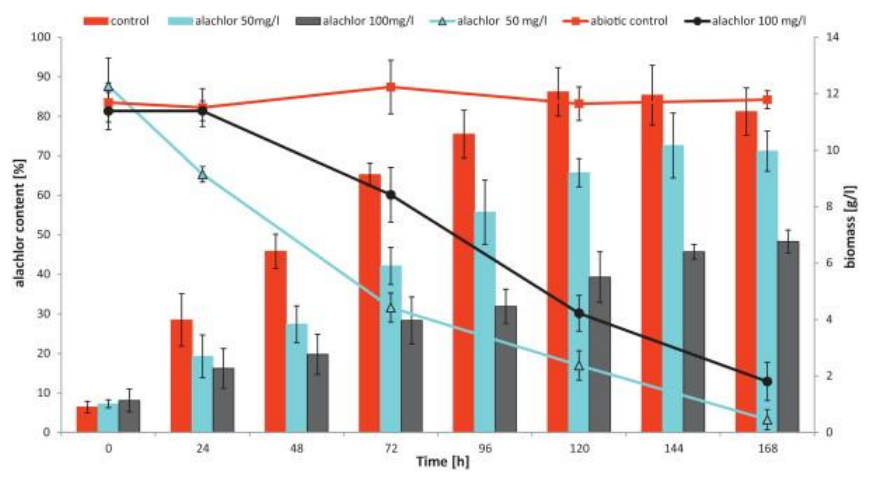

Fig. 1. The fungal growth and alachlor degradation by P. marquandii cultures on Sabuoraud medium containing alachlor at concentrations 50 and $100 \mathrm{mg} \mathrm{L}-1$.

After 7days of incubation only 3.3 and $20.1 \%$ of alachlor added at the initial concentrations of 50 and $100 \mathrm{mg} \mathrm{L}^{-1}$ were detected. It was noteworthy that $70 \%$ of the supplied alachlor disappeared as soon as after $72 \mathrm{~h}$, when xenobiotic was introduced at a dose of $50 \mathrm{mg} \mathrm{L}$ 1 . Our results are comparable with the results of most papers investigating microbial transformation of alachlor by streptomycetes, yeast and filamentous fungi via cometabolism [27,28,29,30,34].

\subsection{Qualitative analysis of alachlor biodegradation}

Alachlor fragmentation patterns were initially examined for a proper IDA LC-MS/MS method setup. In the ER scan (Fig. 2 A) a molecular ions cluster of alachlor showed a typical isotopic distribution for a compound containing one chlorine atom. Several EPI experiments were made to collect mass spectra at different collision energies (CE) from each isotopic form. The most important data from EPI experiments were collected from molecular ion $M$ and $M+2$ isotopes, which revealed the presence of chlorine atoms in the following mass spectrum fragments: $238 \mathrm{~m} / \mathrm{z}, 224 \mathrm{~m} / \mathrm{z}, 220 \mathrm{~m} / \mathrm{z}, 210 \mathrm{~m} / \mathrm{z}, 208 \mathrm{~m} / \mathrm{z}$, $90 \mathrm{~m} / \mathrm{z}$ and $77 \mathrm{~m} / \mathrm{z}$ (Fig. 2 B). Ion clusters around $78 \mathrm{~m} / \mathrm{z}$ and $91 \mathrm{~m} / \mathrm{z}$ are typically a result of aromatic ring presence and that is why we did several MS3 scans to have a deeper insight into the process of alachlor fragmentation (Fig. 2C). The results of such approach showed that, while fragments above $162 \mathrm{~m} / \mathrm{z}$ are mostly a result of fragmentations and rearrangements of dimethyl ether $\left(\mathrm{C}_{2} \mathrm{H}_{6} \mathrm{O}\right)$ and chloracetaldehyde $\left(\mathrm{C}_{2} \mathrm{H}_{3} \mathrm{ClO}\right)$ substituents attached to nitrogen atom, fragments equal to or below $162 \mathrm{~m} / \mathrm{z}$ come from the fragmentation of the 2,6-diethyl-N-methylaniline structure (methaniminium ion $\mathrm{C}_{11} \mathrm{H}_{16} \mathrm{~N}^{+}$). As it is shown in Figure $2 \mathrm{~B}$ and $2 \mathrm{C}$, ion clusters $77-79 \mathrm{~m} / \mathrm{z}$ and $90-92 \mathrm{~m} / \mathrm{z}$ originate from two different types of fragmentation, but chlorine containing fragments are much stronger than fragments coming from the ring related structure. Having all data, we provided the explanation of alachlor mass spectrum in Fig. 2D and chose ions $117.1 \mathrm{~m} / \mathrm{z}$ and $162.1 \mathrm{~m} / \mathrm{z}$ as the best markers due to their structure, intensity and stability for the IDA method applied in metabolite identification studies.

Samples for qualitative analysis were collected in 0, 24, 72, 120 and $168 \mathrm{~h}$ of culturing and included corresponding biotic and abiotic controls acting as a reference for alachlor metabolites searching. All samples were prepared in triplicates and examined by the IDA LCMS/MS method. Based on mass spectra analysis, we found 10 metabolites. All of them underwent characteristic fragmentation in the EPI scan confirming the presence the of 2,6-diethyl-Nmethylaniline substructure and absence of the chlorine atom 

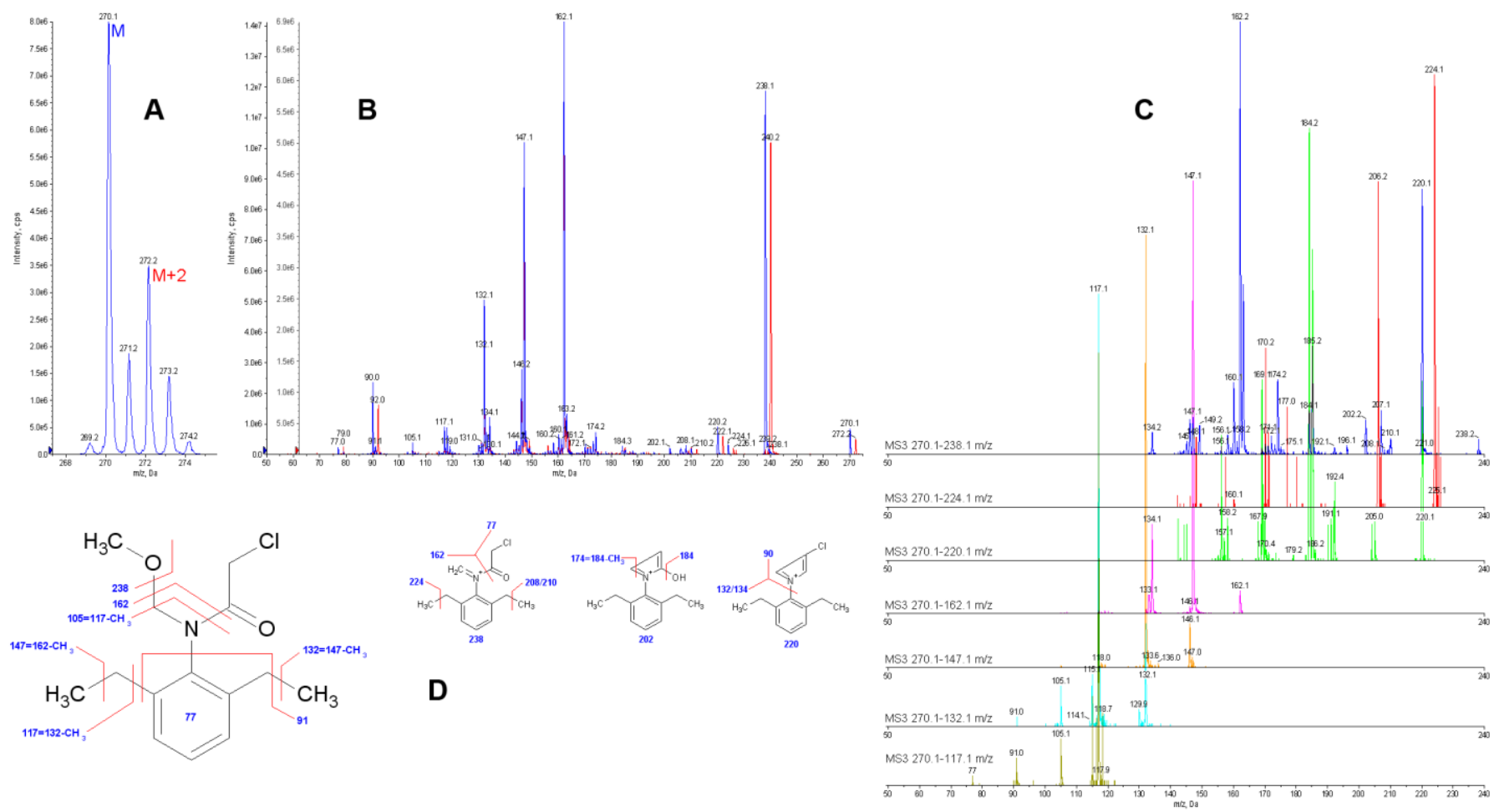

formation. This derivative was also previously detected by us in $P$.

Fig. 2. Mass spectra analysis of alachlor showing their typical fragmentation pattern.

examined in the ER scan. In two cases - RT=8.2 (M=295.1) and $R T=13.9(M=264.2)$ we could not identify the structure further as the $\mathrm{m} / \mathrm{z}$ signals were too weak and difficult to interpret. Examples of mass spectra and their basic interpretation are shown in Fig. 3. The first two examples show mass spectra coming from the compounds with a removed chlorine atom as a result of mono- and dihydroxylation (Fig. $3 \mathrm{~A}$ and $3 \mathrm{~B}$, respectively) of the chloracetaldehyde $\left(\mathrm{C}_{2} \mathrm{H}_{3} \mathrm{ClO}\right)$ substituent of alachlor. Dihydroxylation on C-terminal of the acetaldehyde substituent of $\mathrm{N}-(2,6-$ diethylphenyl)-2,2-dihydroxy- $M$ (hydroxymethoxy)methyl]acetamide can be reasonably explained and confirmed by rearrangements between neighbour chains, which results in the formation of ion 63 $\mathrm{m} / \mathrm{z}$. In the case of $\mathrm{N}$-[2-ethyl-6-(2-hydroxyethyl)phenyl]- $\mathrm{N}$ (methoxymethyl)acetamide (Fig. 3C), the fragmentation pattern of the 2,6-diethyl- $\mathrm{N}$-methylaniline substructure is a little different as a result of hydroxylation of one ethyl group at a distal point from the benzene ring. The most important ions confirming this structure are: $176.2 \mathrm{~m} / \mathrm{z}\left(\mathrm{C}_{11} \mathrm{H}_{14} \mathrm{NO}^{+}\right), 158.2 \mathrm{~m} / \mathrm{z}\left(\mathrm{C}_{11} \mathrm{H}_{12} \mathrm{~N}^{+}\right)$formed as a result of $\mathrm{H}_{2} \mathrm{O}$ loss from ion $176.2 \mathrm{~m} / \mathrm{z}, 143.2\left(\mathrm{C}_{10} \mathrm{H}_{8} \mathrm{~N}^{+}\right)$formed as a result of $\mathrm{CH}_{3}$ loss from ion $158.2 \mathrm{~m} / \mathrm{z}$. All the other mass spectra of potential metabolites were examined and interpreted in a similar way. The summary of qualitative analysis is presented in Supplementary Data (Table S1)

Relative intensity of the alachlor metabolites checked in the samples collected during the culture of $P$. marquandii revealed that the majority of them appeared at a relatively low level from $72 \mathrm{~h}$ and reached their maximum at 120-168 h. N-[2-ethyl-6-(2hydroxyethyl)phenyl]- $N$-(methoxymethyl)acetamide (6) appeared only at $168 \mathrm{~h}$ of incubation. Parallel analysis of metabolite peaks area tendencies and one to each other area ratio in the following hours of the experiment (Supplementary Data, Fig S1) helped us formulate the alachlor biodegradation pathway showed in Fig. 4. The main route of biodegradation starts with oxidative dechlorination resulting in the formation of $\mathrm{N}$-(2,6-diethylphenyl)-2-hydroxy- $\mathrm{N}$ (methoxymethyl)acetamide (5). This compound undergoes consecutive hydroxylations of terminal carbon atoms of both dimethyl ether and hydroxyacetaldehyde substituents attached to the nitrogen atom of the 2,6-diethyl-N-methylaniline substructure. Oxidation reactions generate various di- or trihydroxy derivatives and \{(2,6-diethylphenyl)[(hydroxymethoxy)methyl]amino\}(oxo)acetic acid (7). On the other hand, this route also leads to methylation of the hydroxyl group as a next step after full oxidation of terminal carbons and formation of $N$-(2,6-diethylphenyl)- $N$ [(dihydroxymethoxy)methyl]-2-hydroxy-2-methoxyacetamide (10). Other side reactions are probably reductive dechlorinations that start from $N$-(2,6-diethylphenyl)- $N$-(methoxymethyl)acetamide (8) marquandii cultures analyzed with GC/MS application [31]. One route leads to a loss of chloracetaldehyde and methanol from alachlor and the other one leads to hydroxylation of the ethyl group attached to a benzene ring after previous dechlorination of the chloracetaldehyde substituent (6).

Alachlor byproducts have been often identified in bacteria enriched soil samples or microbial cultures $[18,27,28]$. Nevertheless, only few papers presented metabolic pathway of alachlor transformation by microorganisms. Tiedje and Hagedorn [29] described alachlor conversion by soil fungus Chaetomium globosum and identified four metabolites: 2-chloro-2',6'-diethylacetanilide, 2,6-diethyl- $N$ (methoxymethyl)aniline, 2,6-diethylaniline and 1-chloroacetyl-2,3dihydro-7-ethylindole. Chlorinated and dechlorinated indole and quinoline derivative compounds were detected as main metabolites of soil actinomycetes [30]. The metabolic pathway of alachlor biotransformation, proposed by us, differs from this provided by Tiedje and Hagedorn [29] and Sette et al. [30]. Alachlor was metabolized by $P$. marquandii mainly by hydroxylation. Both hydroxylation of the $\mathrm{N}$-alkyl group and benzylic hydroxylation of ethyl side chains occurred, although the first type of reaction dominated. Our results are in opposition to the findings of Hapeman-Somich [35], Pothuluri et al. [27] and Qiang et al. [16] showing that ethyl chains of alachlor are more susceptible to oxidation. Filamentous fungus Cunninghamella elegans oxidized alachlor at the benzylic position [27]. Pothuluri et al [27] noticed a connection between the preferential hydroxylation of the arylethyl side chain of alachlor and cytochrome P-450 monooxygenase activity. It was well documented that the fungus $C$. elegans can metabolize different xenobiotics with an involvement of cytochrome P-450 [27,36,37]. Considering such a possibility, we investigated whether $P$. marquandii could transform alachlor in the presence of cytochrome P-450 inhibitors proadifen (SKF 525-A) and 1-aminobenzotriazole (Fig.5). Although during the incubation ca. $20 \%$ mitigation of alachlor degradation in the presence of inhibitors was observed, at $168 \mathrm{~h}$ the differences between the control without inhibitors and the cultures supplied with SKF 525-A and 1-aminonenzotriazole did not exist. The herbicide elimination under inhibitors pressure was effective, suggesting a negligible role of cytochrome P-450 in alachlor metabolism. These results can help to explain the difference in the alachlor hydroxylation by compared fungi.

\subsection{Toxicological study}

Xenobiotic transformations occurring via biooxidation and dechlorination often lead to the substrate detoxification [27]. On the other hand, it is known that mammalian metabolic activation of alachlor involving monooxygenation and conjugation processes can result in the formation of toxic and carcinogenic intermediate 

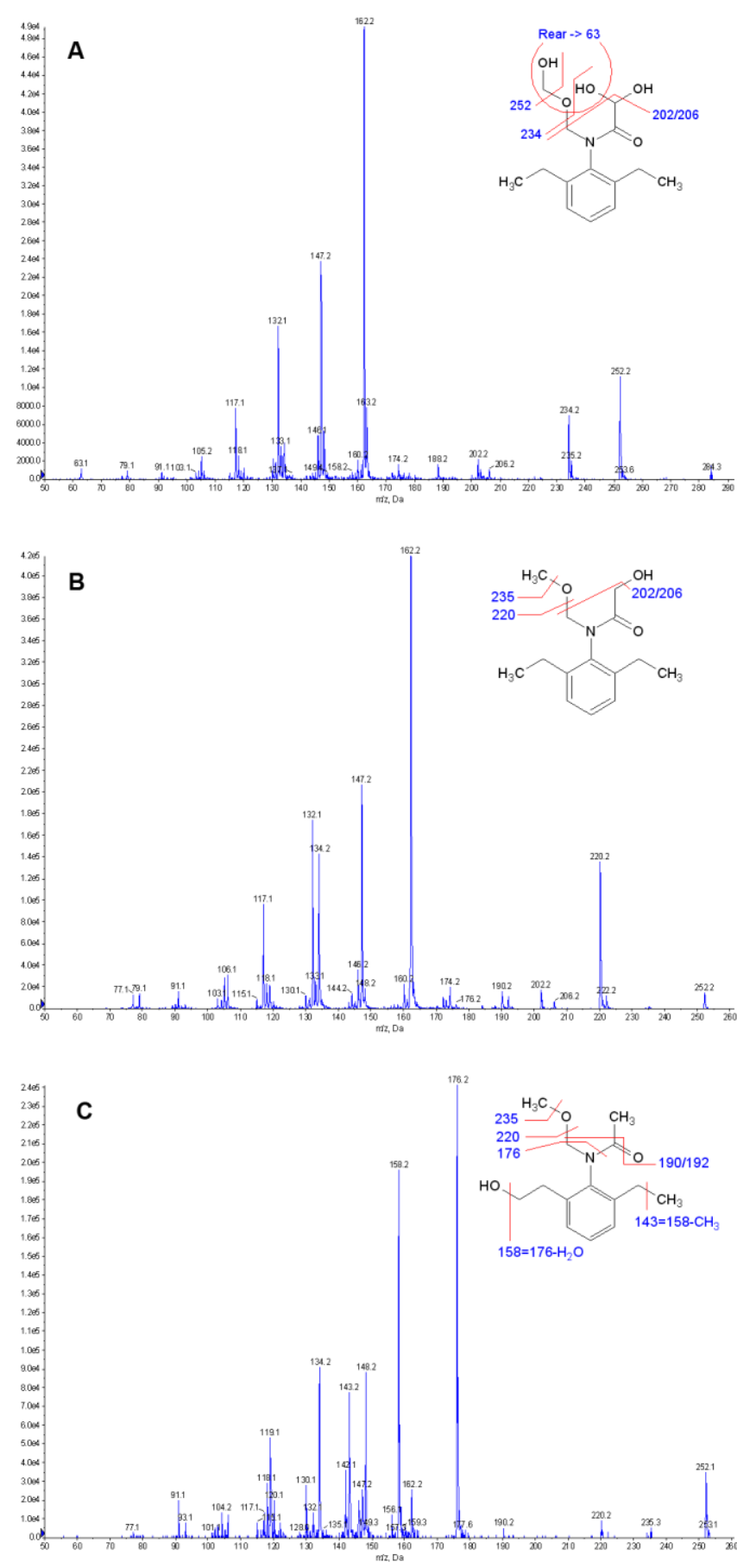

Fig. 3. Mass spectra and fragmentation patterns of exemplary alachlor degradation byproducts and alachlor intermediates originating from $P$. marquandii cultures detectedby LC-MS/MS.

metabolites [38-39]. Therefore, we tested abiotic samples and fungal cultures containing the same concentration of alachlor with the application of Artemia franciscana toxkit. These crustaceans inhabiting aquatics environments with different salinity $\left(5-250 \mathrm{~g} \mathrm{~L}^{-1}\right)$ are commonly used in ecotoxicological studies [40].

Studies concerning alachlor toxicity were conducted with $P$. marquandii extracts, because the diluted supernatants obtained after the fungus cultures demonstrated significant toxicity to $A$. franciscana, which was not observed in the case of extracts in the same dilutions (data not shown). An inhibition of the tested crustacean motility by extracts diluted in saline water after $24 \mathrm{~h}$ incubation was observed and the results were expressed as effect concentration, which inhibited nauplii motility by $50 \%\left(\mathrm{EC}_{50}\right)($ Table 1). The $24 \mathrm{~h} \mathrm{EC}_{50}$ of alachlor (corresponding to the initial alachlor dose) reached $8.17 \pm 1.11$ and $7.35 \pm 2.54 \mathrm{mg} \mathrm{L}^{-1}$ for abiotic and biotic samples and did not show a statistically significant difference $(p<0.05)$. The value of $24 \mathrm{~h} \mathrm{EC}_{50}$ obtained for the alachlor solution without the extraction procedure was $10.80 \pm 2.51 \mathrm{mg} \mathrm{L}^{-1}$. Generally, alachlor has moderate toxicity to aquatic invertebrates. $\mathrm{EC}_{50}$ or $\mathrm{LC}_{50}$

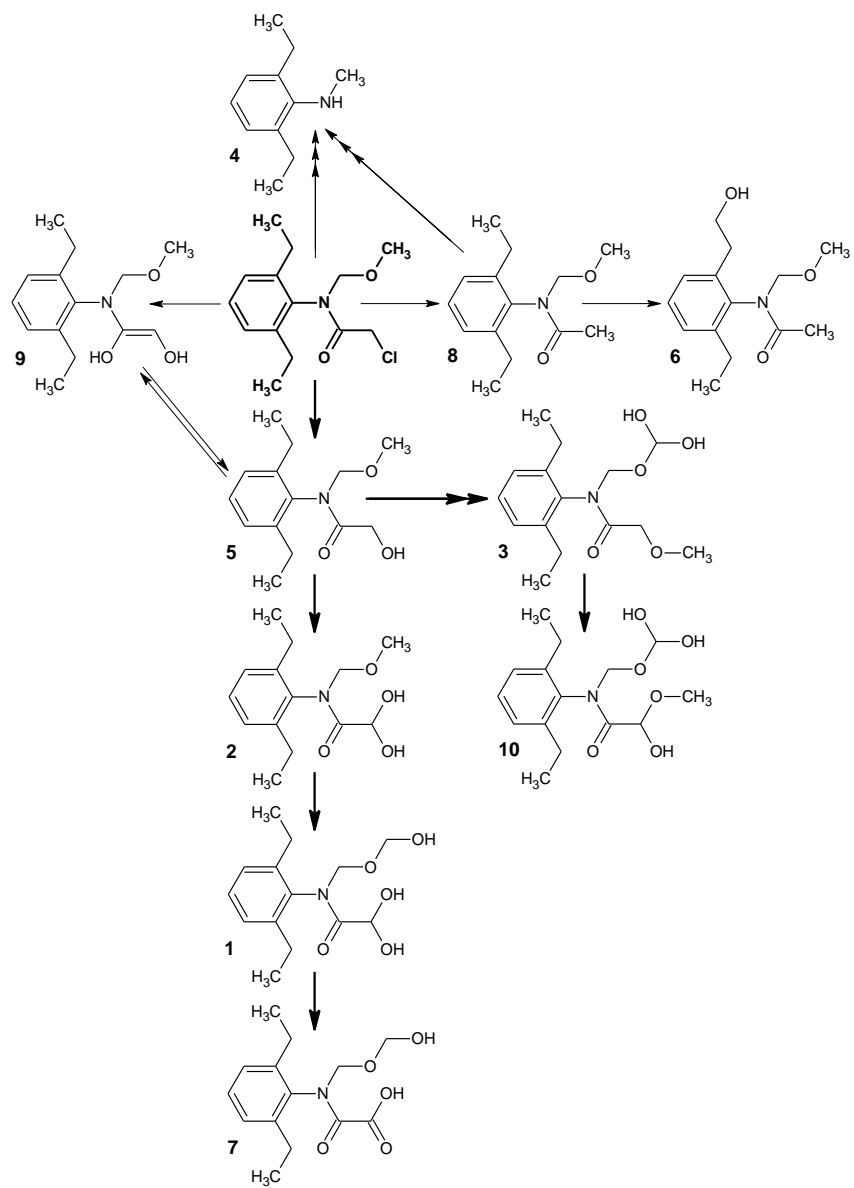

Fig. 4. A proposed pathway of alachlor biotransformation by $P$. marquandii.

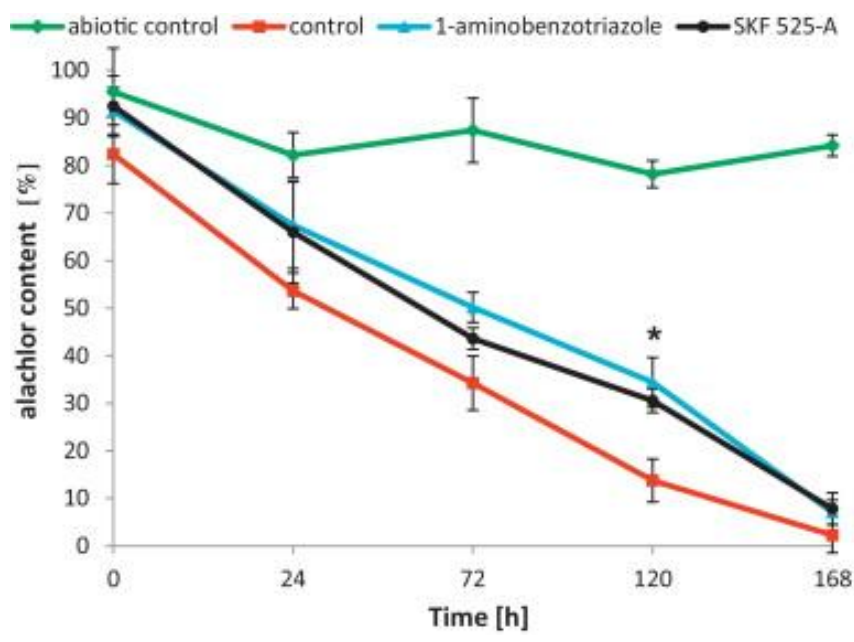

Fig. 5. Effect of cytochrome P-450 inhibitors on alachlor elimination by $P$. mar-quandii. * Significant differences at $p<0.05$.

Table 1. The toxicity test of alachlor samples treated and untreated with $P$. marquandii.

\begin{tabular}{ll}
\hline Samples & $\mathbf{2 4} \mathbf{h ~ E C}_{50}\left[\mathrm{mg} \mathrm{L}^{-1}\right]$ \\
\hline Extract of Sabouraud medium after 7 day- incubation (without $P$. & $8.17 \pm 1.11$ \\
marquandii inoculation) & $7.35 \pm 2.54$ \\
Extract of $P$. marquandii cultures after 7- day incubation & $10.80 \pm 2.51$ \\
Pure alachlor solution (without incubation and extraction) &
\end{tabular}

of alachlor to Daphnia reached $10-13 \mathrm{mg} \mathrm{L}^{-1}$ [41-44]. The toxic effect of pure alachlor solution determined by us was comparable with the acute toxicity of this herbicide to Daphnia. The results of a toxicity assay with $A$. franciscana showed that biotransformation of alachlor by $P$. marquandii did not increase its toxicity. Direct ozonation and $\mathrm{O}_{3} / \mathrm{H}_{2} \mathrm{O}_{2}$ advanced oxidation resulted only in slight mitigation of alachlor toxicity Qiang et al. [16]. The inhibition of D. magna motility 
amounted to $23.3 \pm 5.8 \%$ (after ozonation) and $26.7 \pm 11.5 \%$ (advanced process) in comparison to $33.8 \pm 5.8$ for the untreated control. The lack of a decrease in alachlor toxicity as a result of oxidation by P.marquandii could be caused by the compensating effect of byproducts with lower and higher toxicity. Besides hydroxylated intermediates, $P$. marquandii produced also 2',6'diethyl- $N$-methylaniline (4). It is a derivative of toxic and carcinogenic 2',6'-diethylaniline (DEA), which was reported in many biodegradation studies $[18,29,45]$. Although extracts originating from control fungal cultures without alachlor supplementation did not affect $A$. franciscana in the tested range of dilutions it cannot be ruled out that mycelium produces some toxic metabolites under alachlor exposure, influencing toxkit organisms.

Additionally, some data show that substitution of chlorine by a hydroxyl group did not affect alachlor toxicity [46]. Although degradation of this herbicide by $P$. marquandii did not lead to direct detoxification, dechlorinated metabolites produced by $P$. marquandii can be more easily degraded by other soil microorganisms.

\section{Conclusions}

The obtained results point to $P$. marquandii as a new valuable research model for the study of alachlor degradation, differing from other microscopic soil fungi. The IDA MS/MS analysis of fungal cultures extracts resulted in the identification of ten alachlor metabolites. The pathway of the herbicide degradation involved mainly dechlorination and oxidation reactions. We did not observe an increase in toxicity during alachlor biooxidation by $P$. marquandii cultures examined with the use of $A$. franciscana toxikits, but the appearance of a 2',6'-diethyl- $N$-methylaniline derivative requires more detailed studies to check the safety of potential environmental applications.

\section{Acknowledgement}

This study was supported by the Grant of the National Centre for Science in Cracow, Poland, No UMO-2011/01/B/NZ9/02898.

\section{References}

[1] B. Lauga, N. Girardin, S. Karama, K. Le Ménach, H. Budzinski, R. Duran, Removal of alachlor in anoxic soil slurries and related alteration of the active communities, Environ. Sci. Pollut. Res. 20 (2013) 1089-105.

[2] T.L. Potter, T.L. Carpenter, Occurrence of alachlor environmental degradation products in groundwater, Environ. Sci. Technol. 29 (1995) 1557-63

[3] World Health Organization, Guidelines for drinking-water quality. WHO 2006 http://www.who.int/water sanitation health/dwq/gdwq3rev/en/index.htm

[4] D.M. Tessier, J.M. Clark, Quantitative assessment of the mutagenic potential of environmental degradative products of alachlor, J. Agric. Food Chem. 43 (1995) 2504-12.

[5] L. Fava, P. Bottoni, A. Crobe, E. Funari, Leaching properties of some degradation products of alachlor and metolachlor, Chemosphere 41 (2000) 15038.

[6] J.H. Zhu, X.L. Yan, Y. Liu, B. Zhang, Improving alachlor biodegradability by ferrate oxidation, J. Hazard. Mater. 135 (2006) 94-9. [7] G. Daston, J.C. Cook, R.J. Kavlock, Uncertainties for endocrine disrupters: Our view on progress, Toxicol. Sci. 74 (2003) 245-52.

[8] H.S. Kang, M.C. Gye, M.K. Kim, Effects of alachlor on survival and development of Bombina orientalis (Boulenger) embryos, Bull. Environ. Contam. Toxicol. 74 ( 2005) $1199-1206$

[9] A. Goksoyr, Endocrine disruptors in the marine environment: mechanisms of toxicity and their influence on reproductive processes in fish, J. Toxicol. Environ. Health A 69 (2006) 175-184.

[10] T.B. Hayes, P. Case, S. Chui, D. Chung, C. Haeffele, K. Haston, M. Lee, V.P. Mai, Y. Marjuoa, J. Parker, M. Tsui, Pesticide mixtures, endocrine disruption, and amphibian declines: are we underestimating the impact?, Environ. Health Perspect. 114 (2006) 40-50.

[11] O. Osano, W. Admiral, D. Otieno, Developmental disorders in embryos of the frog Xenopus laevis induced by chloroacetanilide herbicides and their degradation products, Environ. Toxicol. Chem. 21 (2002) 375-379.

[12] S. Snyder, M. Benotti, Endocrine disruptors and pharmaceuticals: implications for water sustainability, Water Sci. Technol. 61 (2010) 145-54.

[13] A. Fucic, M. Gamulin, Z. Ferencic, J. Katic, M. Krayer von Krauss, A. Bartonova, D.F. Merlo, Environmental exposure to xenoestrogens and oestrogen related cancers: reproductive system, breast, lung, kidney, pancreas, and brain, Environ. cancers: reproductive system,

[14] Directive 2008/105/EC of the European Parliament and of the Council of 16 Directive 2008/105/EC of the European Parliament and of the Council of Decree of the Polish Ministry of the Environment from July 2, 2010. 138/934 Decree of the
02.07.2010.

[16] Z. Qiang, C. Liu, B. Dong, Y. Zhang, Degradation mechanism of alachlor during direct ozonation and $\mathrm{O}_{3} / \mathrm{H}_{2} \mathrm{O}_{2}$ advanced oxidation process, Chemosphere 78 (2010) 517-26

[17] M.M. Ballesteros Martín, J.A. Sánchez Pérez, J.L. García Sánchez, L. Montes de Oca, J.L. Casas López, I. Oller, S. Malato Rodríguez, Degradation of alachlor and pyrimethanil by combined photo-Fenton and biological oxidation, J. Haz. Mat. 155 (2008) 342-9.

[18] D.M. Stamper, O.H. Tuovinen, Biodegradation of the acetanilide herbicides alachlor, metolachlor, and propachlor, Crit. Rev. Microbiol. 24 (1998) 1-22.

J. Xu, M. Yang, J. Dai, H. Cao, C. Pan, X. Qiu, M. Xu, Degradation of acetochlor by four microbial communities. Bioresour. Technol. 99 (2008) 7797-802.

[20] P.M. White, T.L. Potter, A.K. Culbreath, Fungicide dissipation and impact on metolachlor aerobic soil degradation and soil microbial dynamics, Sci. Total Environ. 408 (2010) 1393-1402.
[21] L. Zucconi, C. Ripa, F. Alianiello, A. Benedetti, S. Onofri, Lead resistance sorption and accumulation in a Paecilomyces lilacinus strain, Biol. Fert. Soil 37 (2003) $17-22$.

[22] M. Słaba, M. Bizukojć, B. Pałecz, J. Długoński, Kinetic study of toxicity of zinc and lead ions to the heavy metals accumulating fungus Paecilomyces marquandii, Bioprocess Biosyst. Eng. 28 (2005) 185-97.

[23] X. Zeng, J. Tang, H.Yin, X. Liu, P. Jiang, H. Liu, Isolation, identification and cadmium adsorption of a high cadmium-resistant Paecilomyces lilacinus, African J. Biotechnol. 9 (2010) 6525-33. [24] E. Estévez, M.C. Veiga, C.Kennes, Biofiltration of waste gases with the fung
Exophiala oligosperma and Paecilomyces variotii, Appl. Microbiol. Biotechnol. 67 (2005) 563-68.

[25] H. Gradišar, J. Friedrich, I. Križaj, R. Jerala, Similarities and specificities of fungal keratinolytic proteases: comparison of keratinases of Paecilomyces marquandi and Doratomyces microsporus to some known proteases. Appl. Environ. and Doratomyces microsp

[26] Z. Liu, D. Zhang, Z. Hua, J. Li, G. Du, J. Chen, A newly isolated Paecilomyces sp. WSH-L07 for laccase production: isolation, identification, and production sp. WSH-LO7 for laccase production: isolation, identification, and production
enhancement by complex inducement, J. Ind. Microbiol. Biotechnol. 36 (2009) enhancemer $1315-21$.

[27] J.V. Pothuluri, J.P. Freeman, F.E. Evans, E.T. Moorman, C.R. Cerniglia Metabolism of alachlor by the fungus Cunninghamella elegans, J. Agric. Food Chem. 41 (1993) 483-8.

[28] A. Munoz, W.C. Koskinen, L. Cox, M. J. Sadowsky, Biodegradation and mineralization of metolachlor and alachlor by Candida xestobii, J. Agric. Food Chem. 59 (2011). 619-27.

[29] J.M. Tiedje, M.L. Hagedorn, Degradation of alachlor by a soil fungus, Chaetomium globosum, J. Agric. Food Chem. 23 (1975) 77-81.

[30] L.D. Sette, L.A. Mendonca Alves da Costa, A.J. Marsaioli, G.P. Manfio, Biodegradation of alachlor by streptomycetes, Appl. Microbiol. Biotechnol. 64 (2004) 712-17.

[31] M. Słaba, R. Szewczyk, P. Bernat, J. Długoński, Simultaneous toxic action zinc and alachlor resulted in enhancement of zinc uptake by Paecilimyces and alachio

[32] M. Słaba, J. Długoński, Selective recovery of $\mathrm{Zn}^{2+}$ from waste slag from a metalprocessing plant by microscopic fungus Verticillium marquandii, Biotechnol. Lett. 22 (2000) 1699-1704

[33] S. Różalska, R.Szewczyk, J. Długoński, Biodegradation of 4-n-nonylphenol by the non-ligninolytic filamentous fungus Gliocephalotrichum simplex: A proposal of a metabolic pathway, J. Hazard. Mater. 180 (2010) 323-31.

[34] D.R. Shelton, S. Khader, J.S. Karns, B.M. Pogell, Metabolism of twelve herbicides by Streptomyces, Biodegradation, 7 (1996) 129-36.

[35] C.J. Hapeman-Somich, Mineralization of pesticide degradation products. in: L Somasundaram, J.R. Coast, (Eds.), Pesticide Transformation Products: Fate and Significance in the Environment, ACS symposium Series, 459. American Chemical Society, 1991, pp. 133-147.

[36] P. Bernat, J. Długoński, Degradation of tributyltin by the filamentous fungus Cunninghamella elegans, with involvement of cytochrome P-450. Biotechnol. Lett. 24 (2002) 1971-74.

[37] K. Lisowska, J. Długoński, Concurrent corticosteroid and phenanthrene transformation by filamentous fungus Cunninghamella elegans. J. Steroid Biochem. Mol. Biol. 85 (2003) 63-69.

[38] S. Coleman, S. Liu, R. Linderman, E. Hodgson, R.L. Rose, In vitro metabolism of alachlor by human liver microsomes and human cytochrome P450 isoforms, Chem. Biol. Interact. 122 (1999) 27-39.

[39] B.A. Wetmore, A.D. Mitchell, S.A. Meyer, M.B. Genter, Evidence for site-specific bioactivation of alachlor in the olfactory mucosa of the Long-Evans rat, Toxicol. bioactivation of alachlor in the olfactory mucosa of the Long-Evans rat, Toxicol. Sci. 49 (1999) 202-12.

[40] B.S. Nunes, F.D. Carvalho, L.M. Guilhermino, G. Van Stappen, Use of the genus Artemia in ecotoxicity testing, Environ. Pollut. 144 (2006) 453-62.

[41] Alachlor (Lasso), Herbicide Profile 6/85.

[42] Alachlor Sigma-Aldrich, Material Safety Data Sheet.

W.A. Hartman, D.B. Martin, Effects of Four Agricultural Pesticides on Daphnia pulex, Lemna minor, and Potamogeton pectinatus, Bull. Environ. Contam. Toxicol. 35 (1985) 646-51.

[44] H. He, G. Chen, J. Yu, J. He, X.Huang, S. Li, Q. Guo, T. Yu, H. Li, Individual and joint toxicity of three chloroacetanilide herbicides to freshwater cladoceran Daphnia carinata, Bull. Environ. Contam. Toxicol. 90 (2013) 344-50.

[45] C.Z. Chen, C.T. Yan, P.V. Kumar, J.W. Huang, J.F. Jen, Determination of alachlor and its metabolite 2,6-diethylaniline in microbial culture medium using online microdialysis enriched-sampling coupled to high-performance liquid chromatography, J. Agric. Food Chem. 59 (2011) 8078-85.

[46] J.K. Lee, Degradation of the herbicide alachlor by soil microorganisms. Korean J. Environ. Agric. 3 (1984) 1-9. 